\title{
SEISMIC RESPONSE REDUCTION OF BUILDING STRUCTURES USING A SEMI-ACTIVE CONTROL SYSTEM BASED ON A BRAIN EMOTIONAL LEARNING CONTROLLER
}

\author{
Manuel T. Braz-César ${ }^{1}$, Rui C. Barros ${ }^{2}$ \\ ${ }^{1}$ Polytechnic Institute of Bragança \\ Campus de Santa Aplónia - Apt. 134 - 5301-857 Bragança - Portugal \\ e-mail: brazcesar@ipb.pt \\ ${ }^{2}$ Faculty of Engineering of the University of Porto \\ Rua Dr. Roberto Frias, s/n 4200-465 Porto - Portugal \\ rcb@fe.up.pt
}

Keywords: BELBIC controller, BEL controller, semi-active control, MR damper.

\begin{abstract}
The present paper investigates the effectiveness of a bio-inspired semi-active controller to reduce seismic-induced vibrations in building structures. The control system is based on the use of a MR damper in combination with the so-called Brain emotional learning based intelligent controller (BELBIC), which is an intelligent controller based on the model of Limbic system of brain. A general case for a three degrees of freedom building structure excited by the El Centro earthquake will be used to demonstrate how a semi-active control system comprising a MR damper in a non-collocated configuration can reduce the structural response under seismic loading. Hence, the key objective of this study will be to evaluate and verify the efficiency of a MR damper in controlling the level of vibrations in a three degrees of freedom building structure by means of a BEL controller. A comparison between uncontrolled and controlled structural responses are used to validate the performance and efficiency of the proposed semi-active controller.
\end{abstract}




\section{INTRODUCTION}

The Brain Emotional Learning (BEL) controller is a novel bio-inpired control model based on the emotional learning mechanism of the brain limbic system, which has been employed to develop feedback controllers for complex control problems [1-5]. Essentially the BEL controller comprises four main components, i.e, the amygdala (Am), the orbitofrontal cortex (OC), the sensory cortex (SC) and the thalamus (Th). The amygdala and the orbitofrontal cortex are used to process the emotional signal (SE) while the sensory cortex and the thalamus receives and processes sensory inputs (SI). Sensory inputs (SI) are processed in the thalamus initiating the process of response to stimuli and passing those signals to the amygdala and the sensory cortex. Then, the sensory cortex operates by distributing the incoming signals properly between the amygdala and the orbitofrontal cortex. In this controller, the learning procedure is mainly processed in the orbitofrontal cortex and is based on the difference between an expected punishment or reward and the received punishment or reward (Rew). The perceived punishment/reward (ES) is processed in the brain using learning mechanisms while the received punishment/reward represents an external input. If these signals are not identical, the orbitofronal cortex inhibits and restrains the emotional response for further learning. Otherwise, the controller generates an output response $[1,3]$.

The BEL controller presents interesting features that can be exploited to design structural control systems for civil engineering applications. Thus, the following semi-active control system was developed based on this bio-inspired controller. The Simulink model of the BEL controller is depicted in Figure 1.

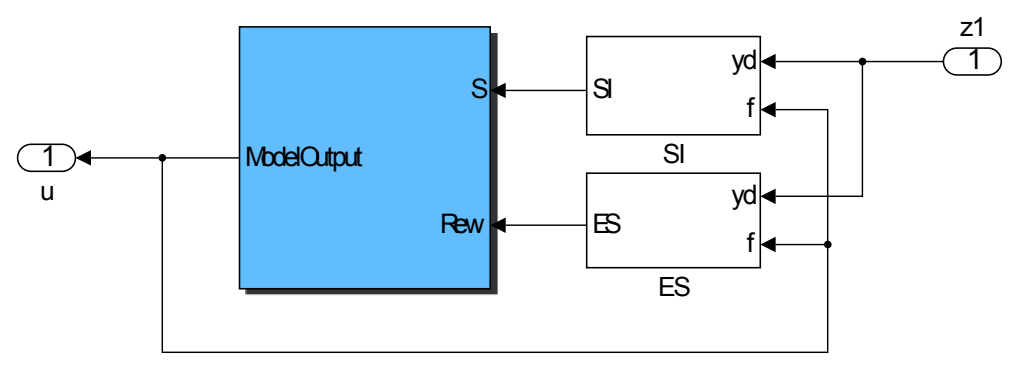

Figure 1: Simulink model of the BEL controller for the three DOFs system.

In this case the sensory input (SI) and the emotional signal (ES) can be related with the system response $y_{d}$ (interstory drifts in this case) and the BEL model output $u$, which are determined using the following equations

$$
\begin{gathered}
S I=w_{1} y_{d}+w_{2} u \\
E S=w_{3} y_{d}+w_{4} \int u d t
\end{gathered}
$$

where $w_{i}$ are weight factors that define the relative importance given to the drift response $\left(z_{1}=y_{d}\right)$ and the output of the BEL controller $(f=u)$. The sensory and emotional outputs are forwarded as the stimuli and the reward/punishment for the BEL controller, respectively. Finally, the BEL control block uses this information to construct a response (model output) that represents the control action.

The BEL algorithm can be also combined with a PID controller to improve the performance of the control system. The PID controller is integrated in the BEL controller as part of the emotional signal, i.e. 


$$
E S=K_{p} y_{d}+K_{I} \int y_{d} d t+K_{D} \frac{d}{d t} y_{d}+w_{4} \int u d t
$$

where $\mathrm{K}_{\mathrm{P}}, \mathrm{K}_{\mathrm{I}}$, and $\mathrm{K}_{\mathrm{D}}$ are weight factors of the PID controller that must be carefully selected to obtain the desired performance [5]. The learning system of both amygdala (Am) and orbitofrontal cortex (OC) are based on internal weight adjusting rules defined by

$$
\begin{gathered}
\frac{d G_{A m, i}}{d t}=\alpha \cdot \mathrm{SI}_{i} \cdot \max \left(0, \mathrm{ES}-\sum \mathrm{A}_{m, i}\right) \\
\frac{d G_{O C, i}}{d t}=\beta \cdot \mathrm{SI}_{i}(\mathrm{MO}-\mathrm{ES})
\end{gathered}
$$

where $\alpha$ is the learning rate of the amygdala, $\beta$ is the learning rate of the orbitofrontal cortex, ES and MO are the emotional signal and the model output, respectively. These learning rates represent model parameters that must be adjusted in accordance with the input variables (i.e., structural responses) to achieve the required control action.

The main drawback of the BEL controller is related essentially with the appropriate definition of emotional and sensory signals that are able to represent with sufficient precision the system state and the control objective in order to maximize the performance of the control system. There are numerous optimization methods available for tuning these parameters (e.g. genetic algorithms) although a common approach is to use a trial-and-error procedure.

\section{NUMERICAL MODEL}

Consider a semi-active controlled system subjected to an earthquake ground motion with a control force applied to the first mass (or the first DOF, $x_{1}$ ) as illustrated in Figure 2. The control force intends to reduce the response of the system and can be achieved placing an actuator between the base and the first mass. The damper force can be changed using a control system comprising a controller that monitors the system response and computes the required damping force that should be applied to the system changes the system response in order to improve its structural performance. An effective semi-active control involves an appropriate control algorithm that can take advantage of the dissipative properties of the control device. There are several approaches available in the literature to control semi-active devices (further information about semi-active control algorithms is provided in $[7,8])$.

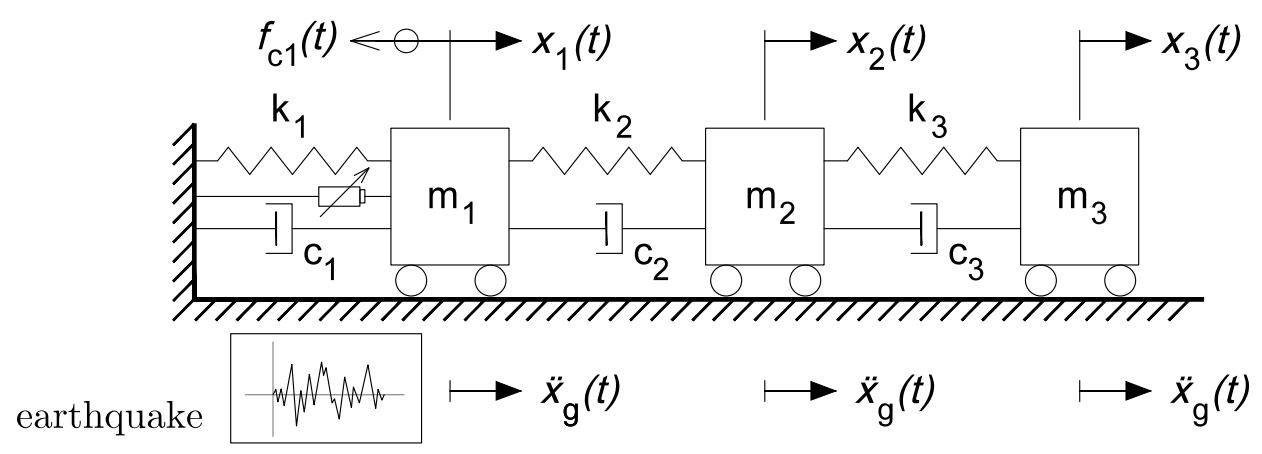

Figure 2: Schematic representation of a 3DOFs system under earthquake excitation - Semi-active control with a MR damper at the first floor. 
MR dampers are semi-active devices in the sense that they are passive actuators with adjustable properties, i.e., they operate by following the response of the system instead of working against the structure motion like in the case of active devices. Also, they cannot be directly controlled to generate a specific damper force because the damper response is dependent on the local motion of the structure where the device is located. A practical approach to control the MR damper it to adjust the voltage applied to the current driver to change the damper force. In this context, the following rules are used to design the control laws [8]:

i. The control voltage to the device is limited ranging between zero voltage input (passive OFF case) and the maximum value of the operating voltage/current Vmax (passive ON case);

ii. For a fixed set of states, the magnitude of the applied force increases and decreases when the voltage input increases and decreases, respectively.

As already has been stated, the structure is equipped with a passive control system comprising a MR damper (Lord RD-1005-03 model) located between the ground floor and the first floor which can operate in two modes: as a passive energy dissipation device and as a semi-active actuator whose control action is being commanded by a BEL based controller. In this case, the modified Bouc-Wen model was selected to simulate the behaviour of the MR damper. The numerical formulation and the corresponding model parameters are presented in Table 1 [9]. Besides, the first-order time lag involved in the current driver/electromagnet during a step command signal must be included in the numerical model of the device, which in this case is defined by a first order filter $\left(\eta=130 \mathrm{sec}^{-1}\right)$.

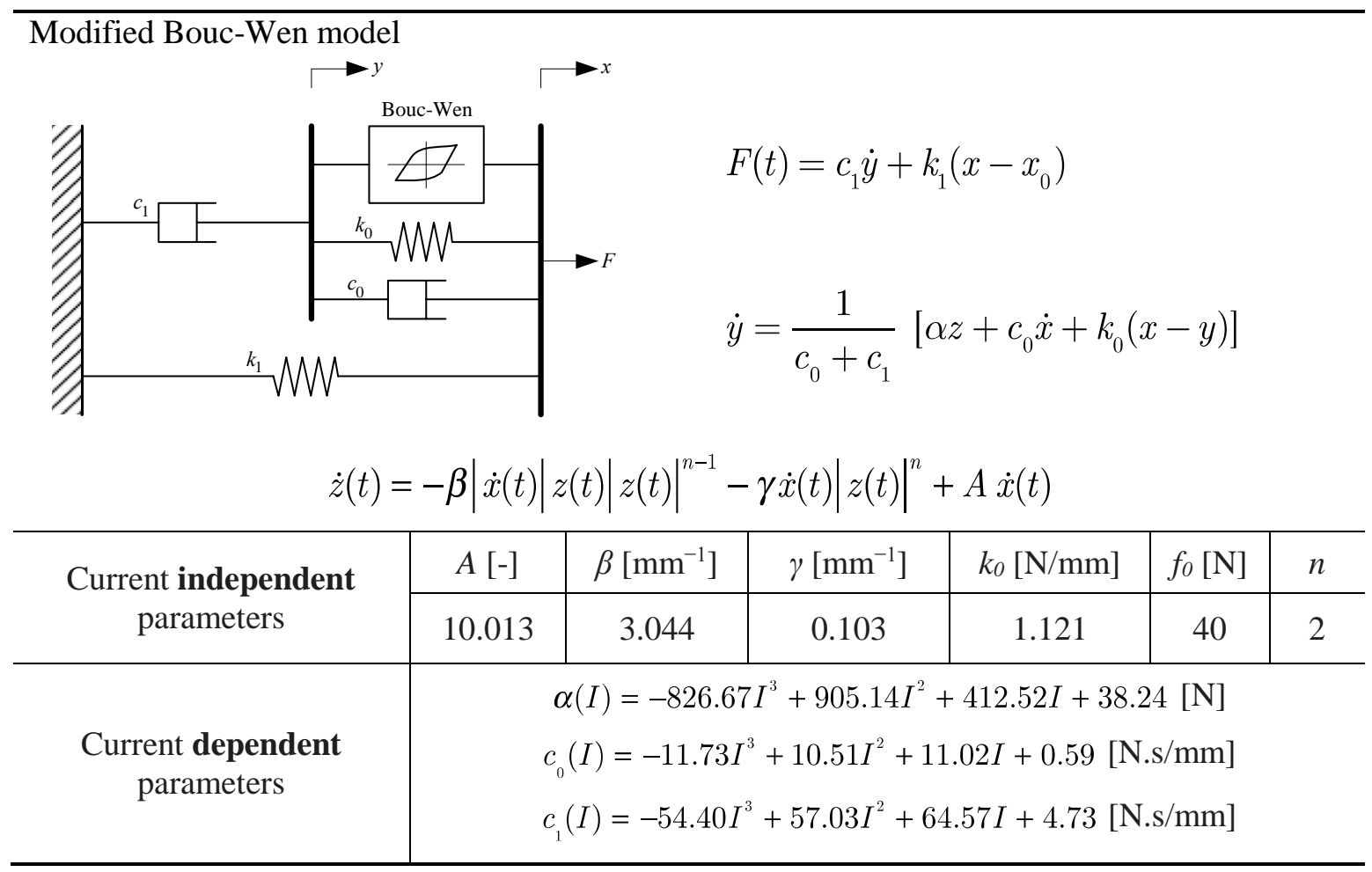

Table 1 - Modified Bouc-Wen model - Parameters of the RD-1005-3 MR damper [9]. 
In what follows, the results of the semi-active control system are compared with the uncontrolled, passive OFF and passive ON responses to evaluate the efficiency of each semi-active control scheme in reducing the structural response. The mass, damping and stiffness matrices of the model structure can be determined as

$$
\begin{aligned}
& \mathrm{M}=\left[\begin{array}{ccc}
m_{1} & 0 & 0 \\
0 & m_{2} & 0 \\
0 & 0 & m_{3}
\end{array}\right]=\left[\begin{array}{ccc}
100 & 0 & 0 \\
0 & 100 & 0 \\
0 & 0 & 100
\end{array}\right] \mathrm{kg} \\
& \mathrm{C}=\left[\begin{array}{ccc}
c_{1}+c_{2} & -c_{2} & 0 \\
-c_{2} & c_{2}+c_{3} & -c_{3} \\
0 & -c_{3} & c_{3}
\end{array}\right]=\left[\begin{array}{ccc}
175 & -50 & 0 \\
-50 & 100 & -50 \\
0 & -50 & 50
\end{array}\right] \mathrm{N} \cdot \mathrm{s} / \mathrm{m} \\
& \mathrm{K}=\left[\begin{array}{ccc}
k_{1}+k_{2} & -k_{2} & 0 \\
-k_{2} & k_{2}+k_{3} & -k_{3} \\
0 & -k_{3} & k_{3}
\end{array}\right]=\left[\begin{array}{rrr}
12 & -6 & 0 \\
-6 & 12 & -6 \\
0 & -6 & 6
\end{array}\right] 10^{5} \mathrm{~N} / \mathrm{m}
\end{aligned}
$$

In this study, the structure will be subjected to the El-Centro ground motion (1940 N-S component with a peak acceleration of $3.42 \mathrm{~m} / \mathrm{s}^{2}$ ). Since the mechanical system seeks to represent a small-scale building, the earthquake signal needs to be decreased to represent the magnitude of displacements that would be observed in experiments tests. Thus, the time was scaled to $20 \%$ of the full-scale earthquake time history as shown in Figure 3.

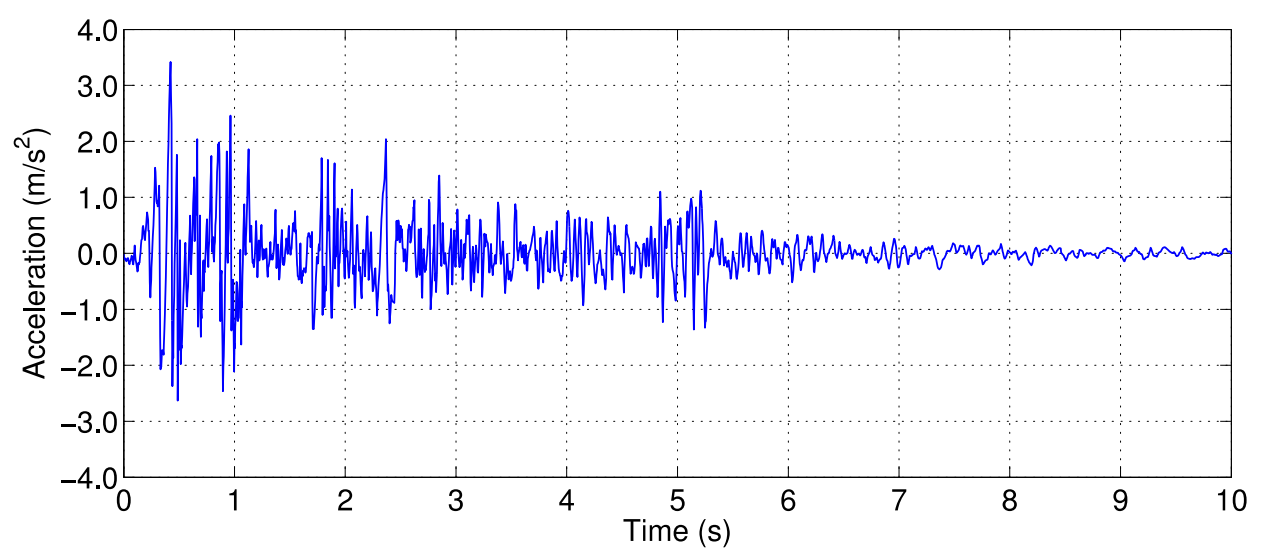

Figure 3: Time-escale El-Centro NS earthquake gound motion $(0.2 \mathrm{t})$.

The state space equation of motion is given by

$$
\dot{z}(t)_{(6 \times 1)}=\left[\begin{array}{cc}
0_{(3 \times 3)} & \mathrm{I}_{(3 \times 3)} \\
-\mathrm{M}^{-1} \mathrm{~K}_{(3 \times 3)} & -\mathrm{M}^{-1} \mathrm{C}_{(3 \times 3)}
\end{array}\right]\left\{\begin{array}{l}
\mathrm{X}(t)_{(3 \times 1)} \\
\dot{\mathrm{X}}(t)_{(3 \times 1)}
\end{array}\right\}+\left\{\begin{array}{c}
0_{(3 \times 1)} \\
-\lambda_{(3 \times 1)}
\end{array}\right\} \underbrace{\ddot{x}_{g}(t)}_{\text {El Centro NS }}
$$

where the column vector $\lambda$ represents the location of the earthquake excitation (i.e., the seismic acceleration). Equation 1 can be written in a simplified form as

$$
\dot{z}(t)_{(6 \times 1)}=A_{(6 \times 6)} z(t)_{(6 \times 1)}+E_{(6 \times 1)} \ddot{x}_{g}(t)
$$

where matrix $A$ represent the system matrix 


$$
A_{(6 \times 6)}=\left[\begin{array}{cc}
0_{(3 \times 3)} & \mathrm{I}_{(3 \times 3)} \\
-\mathrm{M}^{-1} \mathrm{~K}_{(3 \times 3)} & -\mathrm{M}^{-1} \mathrm{C}_{(3 \times 3)}
\end{array}\right]
$$

and $\mathrm{E}$ is the disturbance locating vector given by

$$
E_{(6 \times 1)}=\{0,0,0,-1,-1,-1\}^{T}
$$

The response of the system can be computed using the state space output vector $y(t)$

$$
y(t)=C z(t)+D u(t)
$$

If the system displacements, velocities and accelerations are required, then

$$
C_{(9 \times 6)}=\left[\begin{array}{cc}
\mathrm{I}_{(3 \times 3)} & 0_{(3 \times 3)} \\
0_{(3 \times 3)} & \mathrm{I}_{(3 \times 3)} \\
-\mathrm{M}^{-1} \mathrm{~K}_{(3 \times 3)} & -\mathrm{M}^{-1} \mathrm{C}_{(3 \times 3)}
\end{array}\right], \quad D_{(9 \times 1)}=\left\{\begin{array}{c}
0_{(6 \times 1)} \\
-\lambda_{(3 \times 1)}
\end{array}\right\}
$$

The uncontrolled response is displayed in Figure 4.
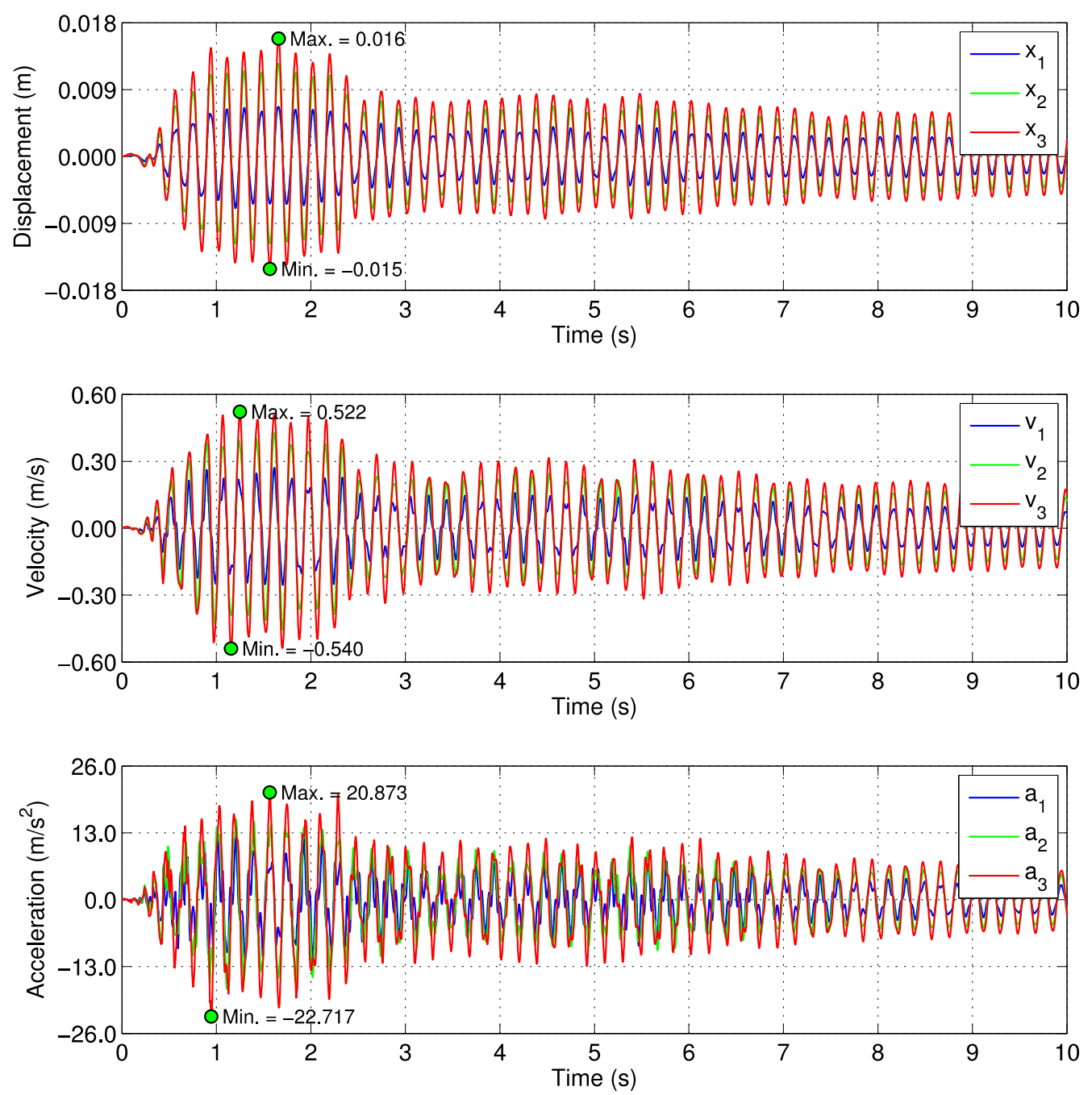

Figure 4: Uncontrolled response of the 3DOFs system. 
It should be noted that the response was obtained with a high excitation level of the El Centro earthquake achieved by scaling up the amplitude of the earthquake signal in $150 \%$. This modification in the excitation signal was used only to amplify the magnitude of the displacements making the system response more compatible with the operating range of the MR damper. The equation of motion of the controlled structure can be defined by a state space formulation as

$$
\dot{z}(t)_{(6 \times 1)}=A_{(6 \times 6)} z(t)_{(6 \times 1)}+B_{c(6 \times 1)} f_{c 1}(t)+E_{(6 \times 1)} \underbrace{\ddot{x}_{g}(t)}_{\text {El Centro NS }}
$$

where $B_{c}$ is an additional matrix accounting for the position of the control forces in the structure and $f_{c}$ is a column vector with the control forces. The location of the control forces is defined by a location matrix $\Gamma$ within $B_{c}$. In this case there is only one control force applied to the first mass and therefore, it follows that

$$
\Gamma_{(3 \times 1)}=\{1,0,0\}^{T}
$$

and then

$$
B_{c(6 \times 1)}=\left\{0,0,0,-\frac{1}{m_{1}}, 0,0\right\}^{T}
$$

Equation 15 can be written in a more compact given that

$$
B_{(6 \times 2)}=\left[\begin{array}{ll}
B_{c(6 \times 1)} & E_{(6 \times 1)}
\end{array}\right]=\left[\begin{array}{cc}
0 & 0 \\
0 & 0 \\
-0 & 0 \\
-\frac{1}{m_{1}} & -1 \\
0 & -1 \\
0 & -1
\end{array}\right], \quad u(t)_{(2 \times 1)}=\left\{\begin{array}{l}
f_{c 1}(t) \\
\ddot{x}_{g}(t)
\end{array}\right\}
$$

and finally

$$
\dot{z}(t)_{(6 \times 1)}=A_{(6 \times 6)} z(t)_{(6 \times 1)}+B_{(6 \times 2)}+u(t)_{(2 \times 1)}
$$

The response of the system can be determined using the state space output vector

$$
y(t)_{(9 \times 1)}=C_{(9 \times 6)} z(t)_{(9 \times 1)}+D_{c(9 \times 1)} f_{c}+F_{(9 \times 1)} \underbrace{\ddot{x}_{g}(t)}_{\text {El Centro NS }}
$$

where $C$ is the same matrix of Equation $14, D_{c}$ comprising the control forces is

$$
D_{c(9 \times 1)}=\left\{0,0,0,0,0,0,-\frac{1}{m_{1}}, 0,0\right\}^{T}
$$

and the column vector $F$ describing the location of the earthquake signal is given by

$$
F_{(9 \times 1)}=\{0,0,0,0,0,0,-1,-1,-1\}^{T}
$$

As for the state space equation, $\ddot{x}_{g}(t)$ represents the seismic excitation loading. 
A new numerical simulation was carried out to obtain the response of the three DOF structure to the time-scale earthquake excitation (i.e., El Centro NS). The system response for the passive OFF case along with the maximum and minimum values of each output variable is displayed in Figure 5 and the damper behaviour is characterized in Figure 6.
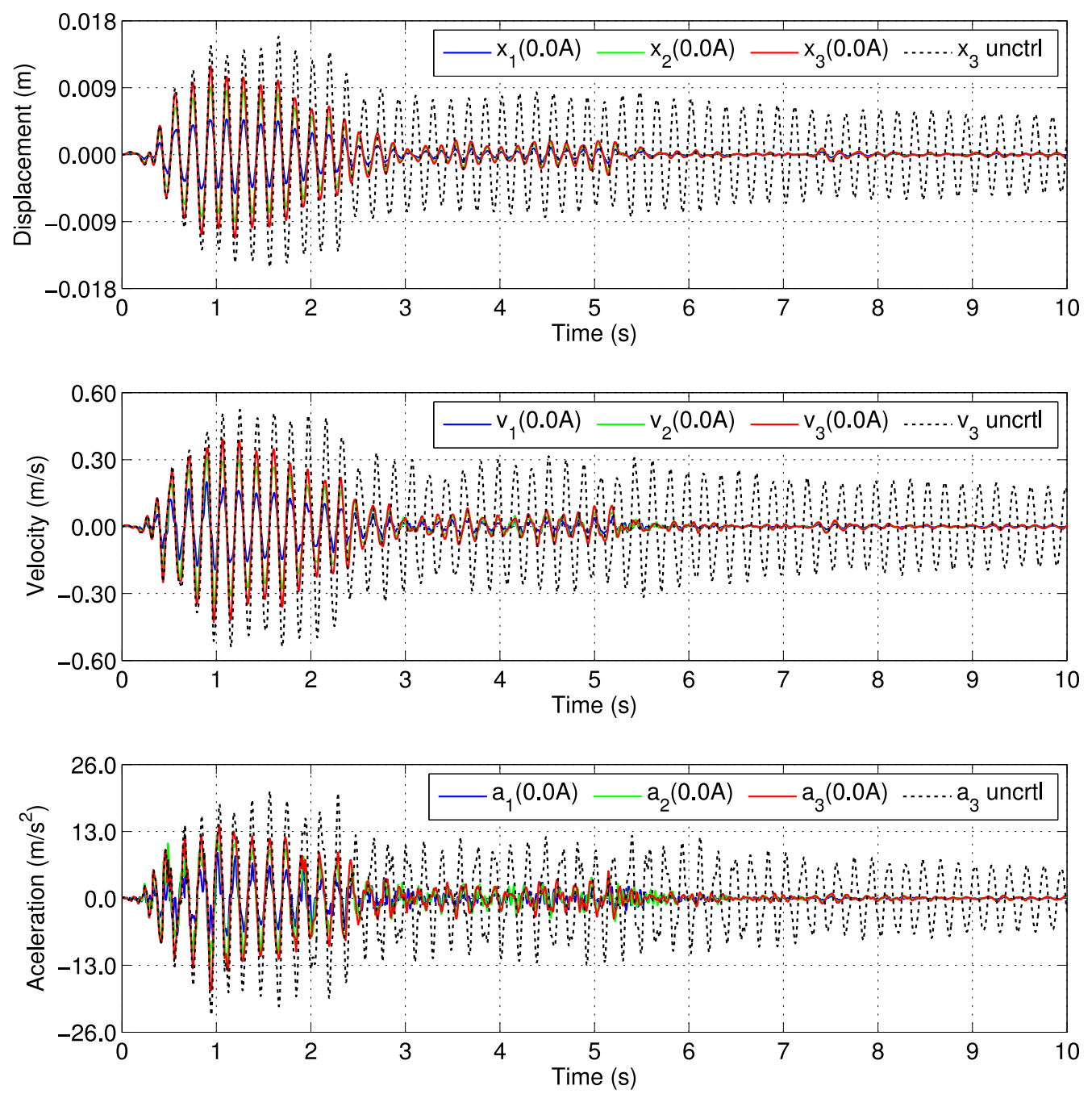

Figure 5: Results with the Modified Bouc-Wen model - Passive OFF case.
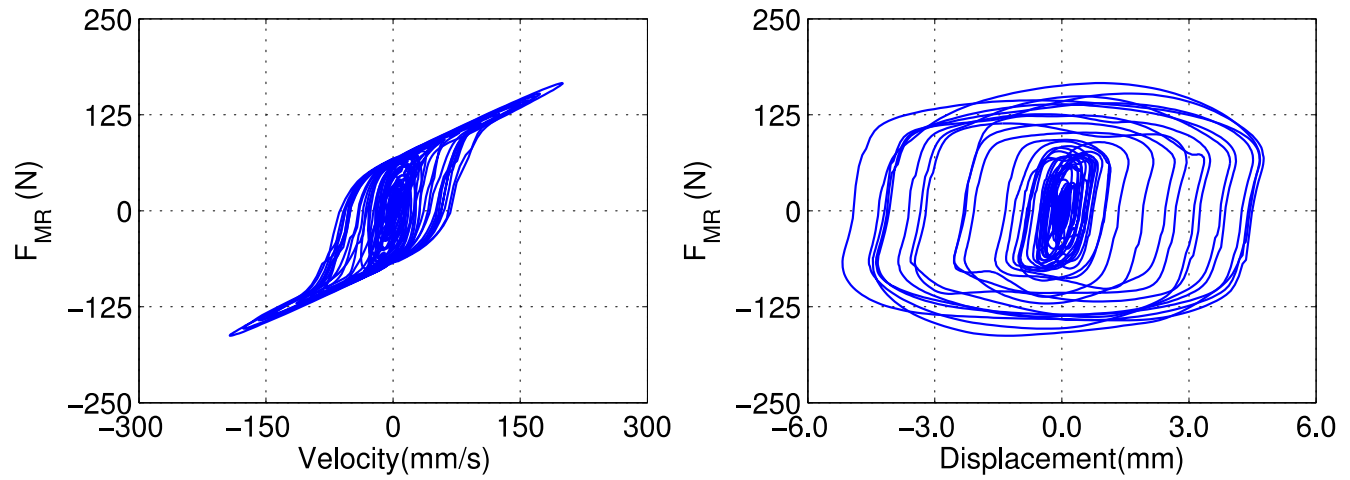

Figure 6: 3DOFs system - RD-1005-03 MR damper control force. Passive OFF case - Modified Bouc-Wen model 
Likewise, a numerical simulation was carried out to obtain the response of the three DOF structure to the time-scale earthquake excitation for the passive $\mathrm{ON}$ mode. The corresponding system response along with the maximum and minimum values of each output variable is displayed in Figure 7 and the damper behaviour is characterized in Figure 8.
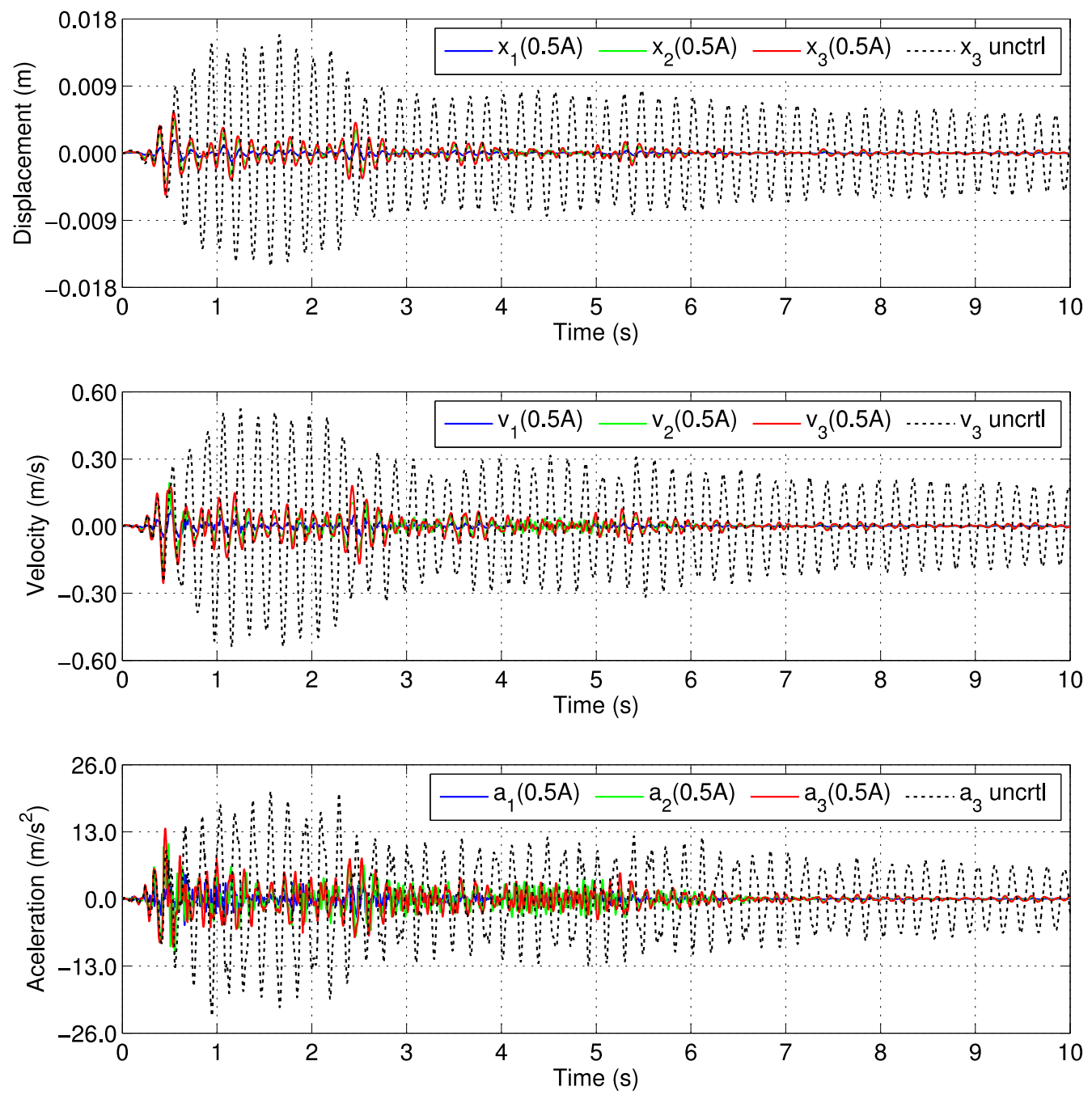

Figure 7: Results with the Modified Bouc-Wen model - Passive ON case.
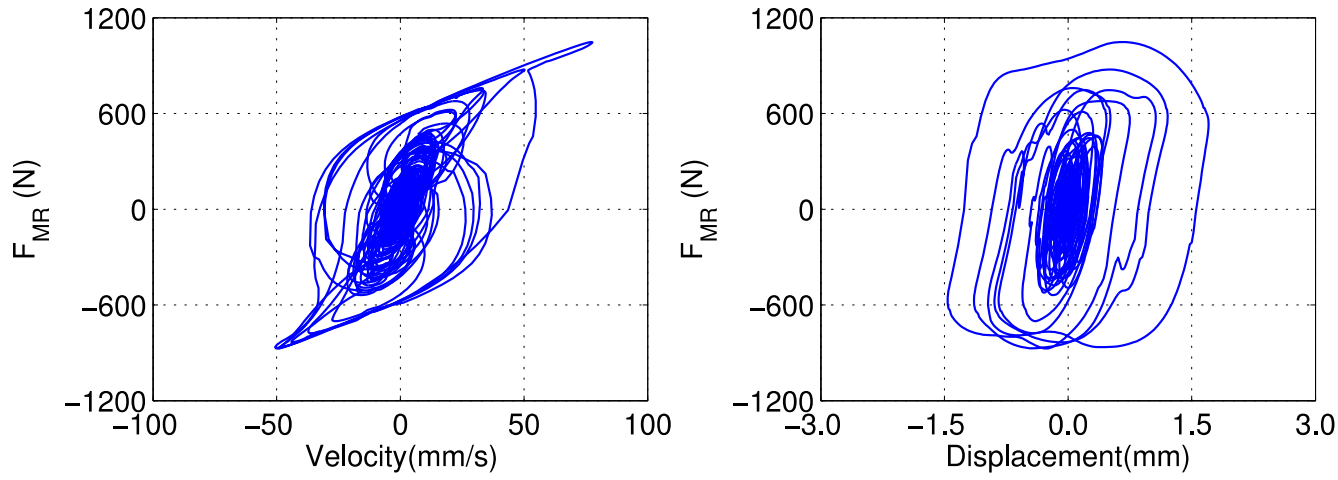

Figure 8: 3DOFs system - RD-1005-03 MR damper control force. Passive ON case - Modified Bouc-Wen model 
The Simulink model of the semi-active control system based on the BEL controller is displayed in Figure 9. As can be observed in this figure, interstory drifs of the building structure constitute the responses of the controlled system used by the BEL controller to determine the desired control force. Subsequently, the required control signal, i.e., the command current is determined from the predicted/desired control force using an inverse Bingham model of the MR damper.

The learning rates for the amygdala and orbitofrontal cortex were defined after a trial-anderror procedure and are computed to be $\alpha=0.8$ and $\beta=0.5$. Likewise, the sensory and the emotional outputs are determined by applying weight factors $w_{1}=2, w_{2}=0.56, w_{3}=2$ and $w_{4}$ $=0.85$, which provide the best structural performance.

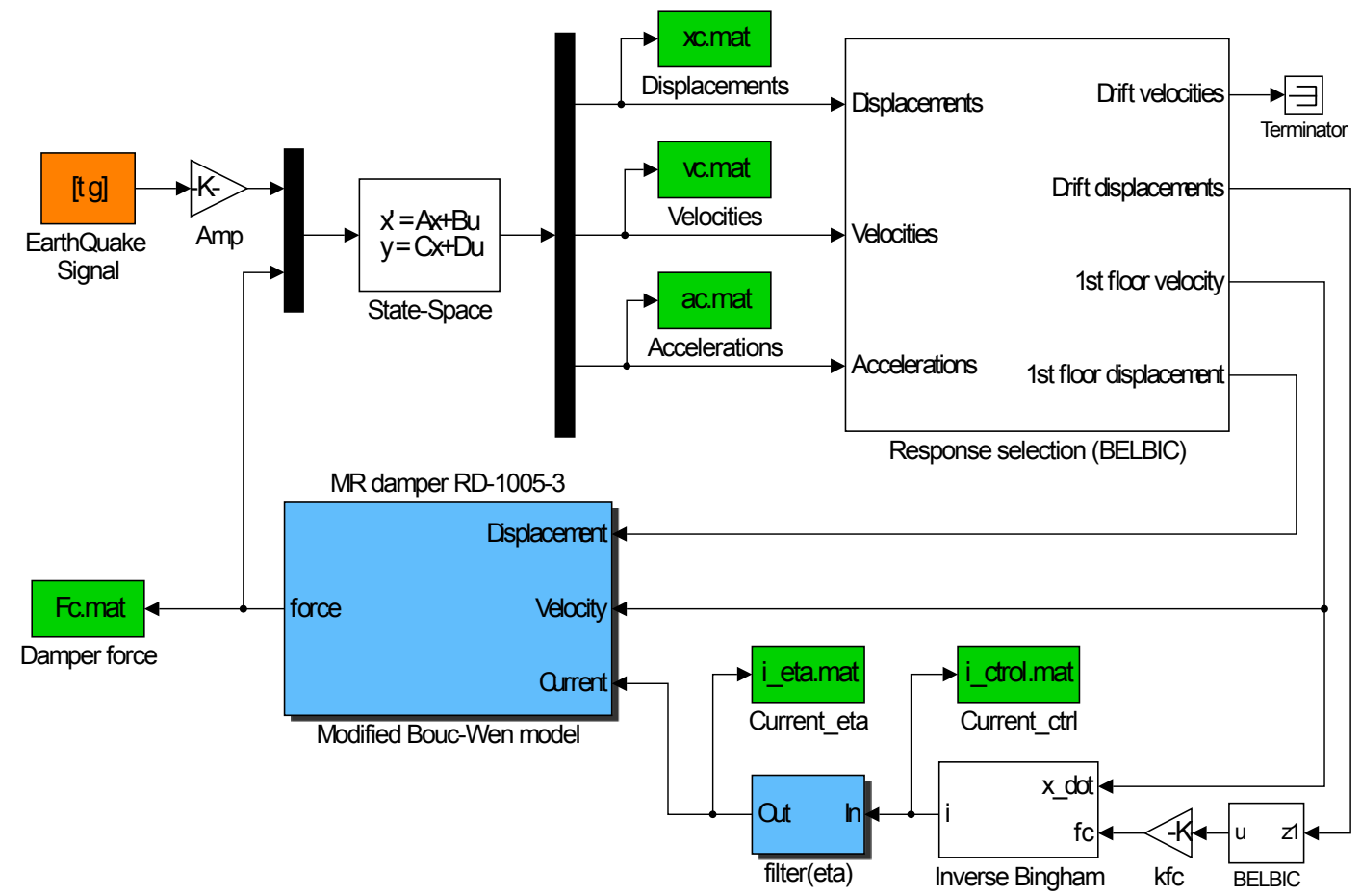

Figure 9: Simulink model of the BEL control system.

The structural responses obtained with the BEL based semi-active control system along with the uncontrolled response of the third floor are displayed in Figure 10. The peak responses of the uncontrolled and controlled systems are listed in Table 2 . The results show the effectiveness of the proposed bio-inspired controller in reducing the response of the structure.

As can be seen, the proposed semi-active control system achieves a good performance in reducing the structural responses using only floor displacements as the reference signals to compute the control action. In fact, the main advantage of the BEL based control system is that only interstory drift responses of the structure are required to determine the control action. This means that the damping force generated during the control process does not need to be monitored, as happens in other controllers such as the clipped-optimal algorithm. Obviously, the main drawback regarding the implementation of the BEL based control system is related with the optimization of the controller parameters.

It should be also noted that the combination of a BEL controller with other control techniques (e.g. PID control) is shown to be able to improve the overall performance of the resultant control system [5]. 

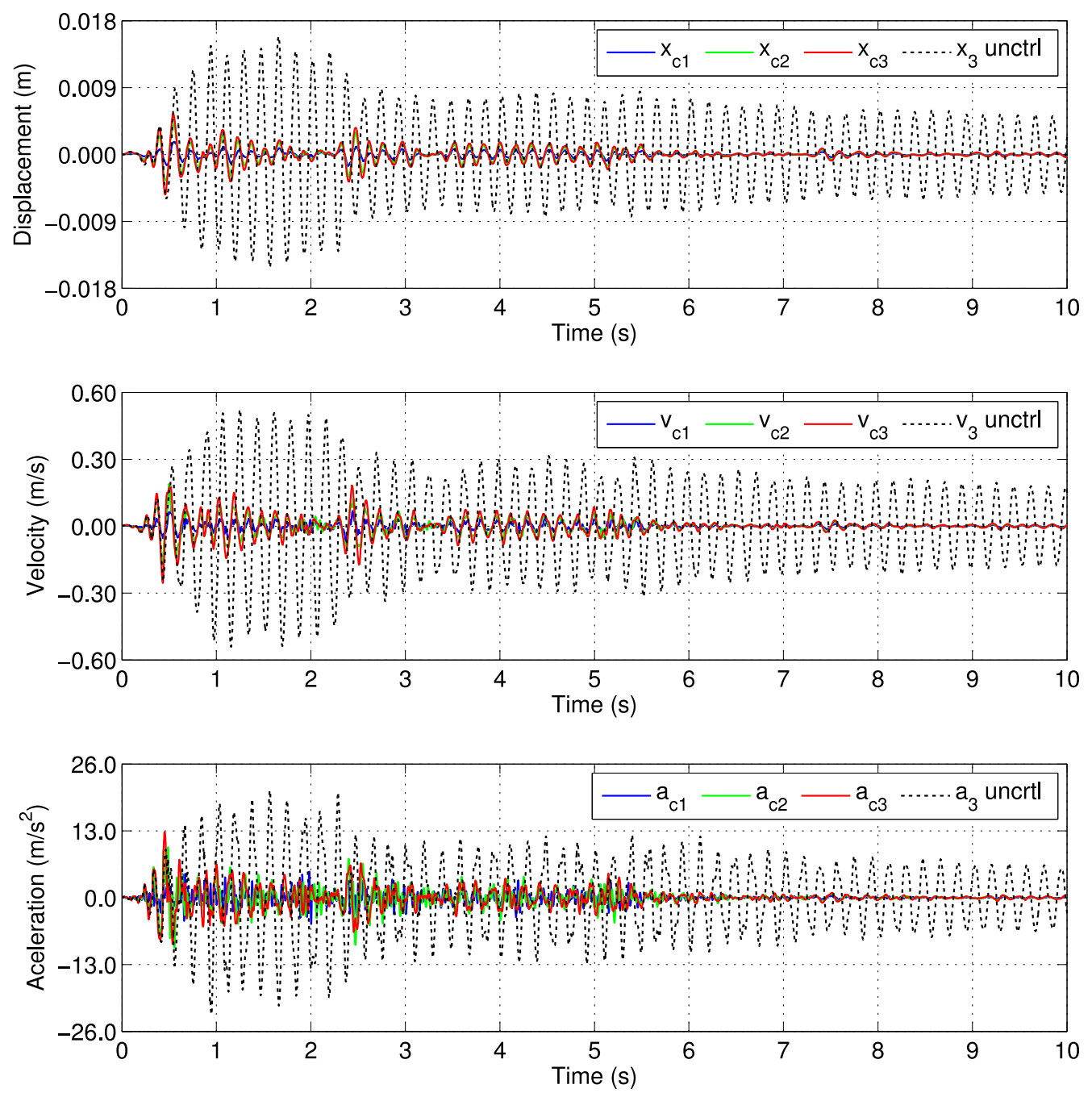

Figure 10: Structural responses obtained with the BEL controller.

\begin{tabular}{|c|c|c|c|c|c|}
\hline \multicolumn{2}{|c|}{ Control strategy } & $x(\mathrm{~cm})$ & $\dot{x}(\mathrm{~cm} / \mathrm{s})$ & $\ddot{x}\left(\mathrm{~cm} / \mathrm{s}^{2}\right)$ & $f(\mathrm{~N})$ \\
\hline \multicolumn{2}{|c|}{ Uncontrolled } & $\begin{array}{l}0.695 \\
1.251 \\
1.587\end{array}$ & $\begin{array}{l}27.09 \\
45.78 \\
54.02\end{array}$ & $\begin{array}{l}1305 \\
1736 \\
2272\end{array}$ & ---- \\
\hline $\begin{array}{l}\text { Passive } \\
\text { OFF }\end{array}$ & $\begin{array}{l}\text { Modified } \\
\text { Bouc-Wen }\end{array}$ & $\begin{array}{l}0.518 \\
0.907 \\
1.191\end{array}$ & $\begin{array}{l}20.02 \\
34.51 \\
42.79\end{array}$ & $\begin{array}{c}999 \\
1358 \\
1791\end{array}$ & 166.4 \\
\hline $\begin{array}{c}\text { Passive } \\
\text { ON }\end{array}$ & $\begin{array}{l}\text { Modified } \\
\text { Bouc-Wen }\end{array}$ & $\begin{array}{l}0.171 \\
0.423 \\
0.560\end{array}$ & $\begin{array}{c}7.77 \\
19.36 \\
25.58 \\
\end{array}$ & $\begin{array}{c}613 \\
1066 \\
1366 \\
\end{array}$ & 1048.9 \\
\hline \multicolumn{2}{|c|}{ Brain Emotinal Learning } & $\begin{array}{ll}0.164 & (-4 \%) \\
0.403 & (-5 \%) \\
0.525 & (-6 \%)\end{array}$ & $\begin{array}{rr}6.80 & (-13 \%) \\
17.88 & (-8 \%) \\
24.19 & (-5 \%)\end{array}$ & $\begin{array}{rr}619 & (1 \%) \\
964 & (-10 \%) \\
1252 & (-8 \%)\end{array}$ & 1014.4 \\
\hline
\end{tabular}

Table 2 - Peak responses under the time-scaled El-Centro earthquake. 
The damper force and the corresponding control signal are presented in Figure 11. As can be observed, the control system uses a continuous control signal to command the MR damper. The hysteretic behaviour of the MR damper during the numerical simulation is portrayed in the force-displacement and force-velocity plots presented in Figure 12. The proposed control system is capable to explore the dissipative nature of this type of actuators.
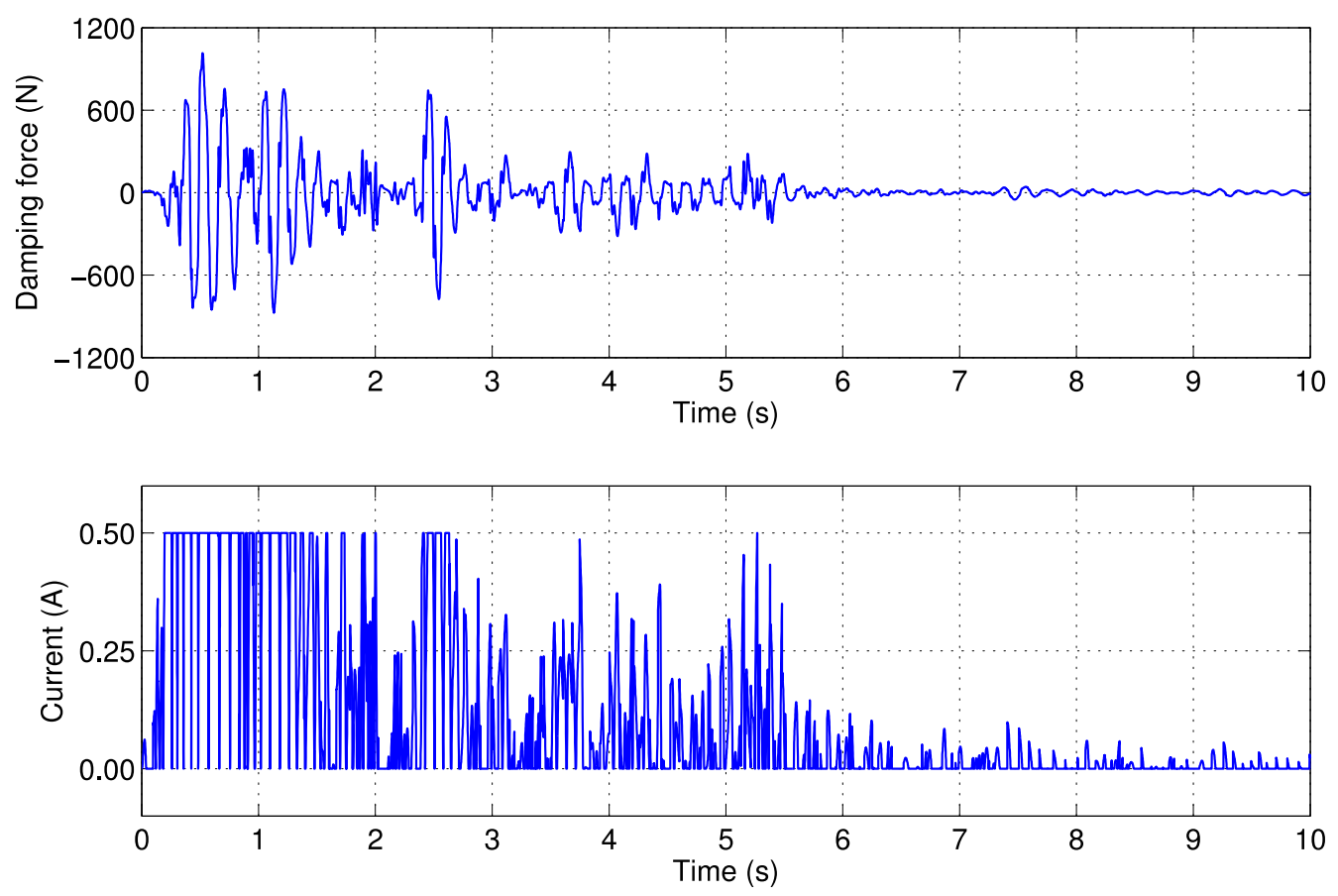

Figure 11: Damper force and corresponding operating current (BEL controller).
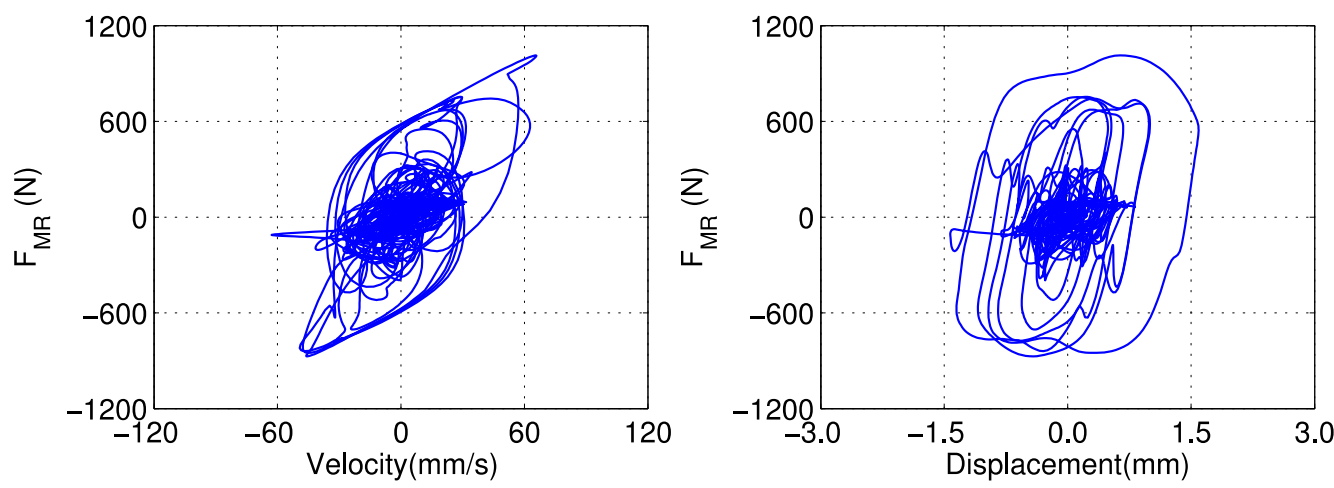

Figure 12: RD-1005-03 MR damper control force (BEL controller).

\section{CONCLUSIONS}

The present article addressed the non-linear hysteretic properties of MR dampers. An experimental testing procedure was carried out to characterize the response of a commercial MR damper and the experimental data were used to develop a numerical model. Some model parameters that must be initially found to construct a realistic numerical response. Thus, an identification routine was developed and the predicted response was compared with the experimental data. The results showed that the selected numerical model is capable to simulate the hysteretic behavior of the MR damper. 


\section{REFERENCES}

[1] C. Lucas, D. Shahmirzadi, and N. Sheikholeslami, Introducing BELBIC: Brain emotional learning based intelligent control, international journal of Intelligent Automation \& Soft Computing, 10 (1): 11-21, 2004.

[2] A. Arami, M. Javan, C. Roshtkhari, C. Lucas, A Fast Model Free Intelligent Controller Based on Fused Emotions: A Practical Case Implementation, pp. 596-602, 2008.

[3] M. Javan, A. Arami, C. Lucas, Emotional Control of Inverted Pendulum System, A soft switching from Imitative to emotional learning, pp. 651-656, 2009.

[4] M. Javan, A. Arami, C. Lucas, Imitative Learning Based Emotional Controller for Unknown Systems with Unstable Equilibrium, International Journal of Intelligent Computing and Cybernetics 2: 334-359, 2010.

[5] Y. Kim, C. Kim and R. Langari, Novel bio-inspired smart control for hazard mitigation of civil structures, Smart Materials and Structures, Vol. 19, No. 11, 2010.

[6] B.F. Spencer Jr., S.J. Dyke, M.K. Sain, J.D. Carlson, Phenomenological model of a magnetorheological damper, Journal of Engineering Mechanics, 123, 230-238, 1997.

[7] S.J. Dyke, B.F. Spencer, A comparison of semi-active control strategies for the MR damper, Proceedings of the IASTED International Conference, Intelligent information Systems, 580-584, 1997.

[8] L.M. Jansen, S.J. Dyke, Semi-active control strategies for MR dampers: comparative study, Journal of Engineering Mechanics, Vol. 125, No. 8, 795-803, 2000.

[9] M. Braz-Cesar, R. Barros, Experimental and numerical analysis of MR dampers, COMPDYN $2013-4^{\text {th }}$ International Conference on Computational Methods in Structural Dynamics \& Earthquake Engineering, 2013. 